\title{
Prolonged fixed dose rate infusion of gemcitabine with autologous haemopoietic support in advanced pancreatic adenocarcinoma
}

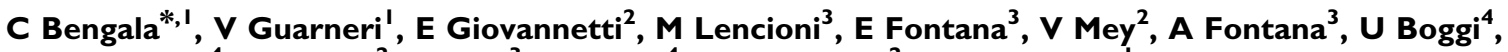 \\ M Del Chiaro ${ }^{4}$, R Danesi $^{2}$, S Ricci ${ }^{3}$, F Mosca $^{4}$, M Del Tacca ${ }^{2}$ and PF Conte ${ }^{1}$
}

'Department of Oncology and Hematology, Division of Medical Oncology, University of Modena and Reggio Emilia, Via del Pozzo7I, Modena 4I l00, Modena, Italy; ${ }^{2}$ Division of Pharmacology and Chemotherapy, University Hospital, Pisa, Italy; ${ }^{3}$ Division of Medical Oncology, University Hospital, Pisa, Italy; ${ }^{4}$ Division of Surgery, University Hospital, Pisa, Italy

\begin{abstract}
This study aimed to define the maximum-tolerated dose (MTD) of fixed dose rate (FDR) of gemcitabine $\left(2^{\prime}\right.$ - $2^{\prime}$-difluorodeoxycitidine) infusion with circulating haemopoietic progenitor support and to evaluate the activity of the treatment. Secondary end points were pharmacokinetic of gemcitabine and difluorodeoxyuridina ( $\mathrm{dFdU}$ ) measured at first course and the activity andexpression profile of cytidine deaminase $(\mathrm{CdA})$ on circulating mononuclear cells. Patients with advanced pancreatic carcinoma received escalating dose of gemcitabine $10 \mathrm{mg} \mathrm{m}^{-2} \mathrm{~min}^{-1}$ every 2 weeks with circulating haemopoietic progenitor support. First dose level was $3000 \mathrm{mg} \mathrm{m} \mathrm{m}^{-2}$ and the doses were increased by $500 \mathrm{mg} \mathrm{m}^{-2}$ until MTD. In all, 23 patients were enrolled. Toxicities were mild or moderate; the only patient treated at $7000 \mathrm{mg} \mathrm{m}^{-2}$ died because of toxicity; therefore; the MTD was established at $6500 \mathrm{mg} \mathrm{m}^{-2}$. The overall response rate was 22.2\%. The AUC of gemcitabine showed a dose-dependent increase, while the AUC of dFdU reached a plateau at $4500 \mathrm{mg} \mathrm{m}^{-2}$. A significant relationship was found between the AUC of dFdU and CdA expression and activity $(P<0.05)$. Moreover, progression rate and survival were significantly related to $\mathrm{CdA}$ expression and activity levels. The activity of high-dose gemcitabine is not superior to that reported with less intensive FDR schedules. The predictive role of CdA expression and activity on outcome deserves further investigation.
\end{abstract}

British Journal of Cancer (2005) 93, 35-40. doi:10.1038/sj.bjc.6602673 www.bjcancer.com

Published online 28 June 2005

(c) 2005 Cancer Research UK

Keywords: cytidine deaminase; fixed dose rate infusion; gemcitabine pharmacokinetic; pancreatic cancer

Pancreatic carcinoma is the fifth most common cause of cancer death in Western countries. At diagnosis, the majority of patients have locally advanced unresectable or metastatic disease for which there is no curative therapy (Evans et al, 1997, p 1054). For many years, 5-fluorouracil has been considered the standard treatment of pancreatic cancer with response rates ranging from 0 to 19\% (Palmer et al, 1994). More recently, gemcitabine $\left(2^{\prime}-2^{\prime}\right.$-difluorodeoxycitidine) has proven activity against a variety of solid tumours including pancreatic cancer (Huang et al, 1991; Rothenberg et al, 1996). A weekly short time (30 min) intravenous (i.v.) infusion of $1000 \mathrm{mg} \mathrm{m}^{-2}$ is the recommended dose and schedule. However, even if effective, this schedule might not to be the optimal one taking into account the metabolism of the drug.

Gemcitabine is a prodrug that is initially phosphorylated by deoxycytidine kinase $(\mathrm{dCK})$ to gemcitabine monophosphate and subsequently to gemcitabine diphosphate and gemcitabine triphosphate. Incorporation of gemcitabine triphosphate into DNA inhibits replication with induction of apoptosis. Phosphorylation of gemcitabine to the monophosphate by deoxycytidine kinase is the rate-limiting step in the accumulation of the active

\footnotetext{
*Correspondence: Dr C Bengala;

E-mail: bengala.carmelo@policlinico.mo.it

Received 21 April 2005; accepted 23 May 2005; published online 28 June 2005
}

diphosphate and triphosphate metabolites. Grunewald et al and Abbruzzese et al have demonstrated that the ability of mononuclear cells to accumulate gemcitabine triphosphate during therapy was saturable and the optimal plasma concentration of gemcitabine that maximised the rate of formation of gemcitabine triphosphate was approximately $20 \mu \mathrm{moll}^{-1}$ (Grunewald et al, 1990, 1991). In these studies, this target plasma gemcitabine concentration and the optimal intracellular accumulation of gemcitabine triphosphate was achieved with dose rates of $10 \mathrm{mg} \mathrm{m}^{-2} \mathrm{~min}^{-1}$ (Abruzzese et al, 1991; Grunewald et al, 1992). Based on these data, a number of phase I trials have explored the possibility to prolong the duration of infusion time; other trials escalated both the dose and infusion duration using a fixed dose rate (FDR) of $10 \mathrm{mg} \mathrm{m}^{-2} \mathrm{~min}^{-1}$ (Abbruzzese et al, 1991; Grunewald et al, 1992; Poplin et al, 1992; Pollera et al, 1997). Tempero et al have compared in a phase II randomised trial the standard gemcitabine infusion in 30 min infusion $v s$ an FDR infusion of $10 \mathrm{mg} \mathrm{m}^{-2} \mathrm{~min}^{-1}$ in pancreatic carcinoma. A significant increase in response rate, a longer median survival and a higher 1-year survival rate was reported in the FDR infusion-treated patients. However, patients receiving the FDR infusion experienced consistently more haematologic toxicity and cumulative myelosuppression was reported (Tempero et al, 2003).

On the basis of these data from this trial and preclinical data suggesting a dose-response relationship (Csoka et al, 1995; Von Hoff, 1996), we have designed a dose-finding phase I trial of 
36

gemcitabine given as prolonged FDR $\left(10 \mathrm{mg} \mathrm{m}^{-2} \mathrm{~min}^{-1}\right)$ infusion every 14 days with haemopoietic progenitor support in patients with advanced pancreatic adenocarcinoma.

End points of the study were to define the maximum-tolerated dose (MTD) of prolonged FDR of gemcitabine plus progenitor blood cells and to evaluate the activity of the treatment in terms of objective responses. Additive end points of the trial were to study the plasma pharmacokinetic of gemcitabine and its metabolite difluorodeoxyuridina (dFdU) following FDR infusion and to evaluate the influence of gene expression and activity of cytidine deaminase $(\mathrm{CdA})$ on clinical outcome.

\section{MATERIALS AND METHODS}

\section{Eligibility}

Patients $\leqslant 75$ years old, performance status $0-1$ (ECOG scale) with histologically confirmed unresectable advanced or metastatic pancreatic carcinoma were eligible for the study. Other eligibility criteria were bidimensionally measurable disease, leucocyte count $\geqslant 3.5 \times 10^{9} 1^{-1}$, platelet count $\geqslant 100 \times 10^{3} 1^{-1}$, haemoglobin level $\geqslant 10 \mathrm{gl}^{-1}$, no active infection, no severe concurrent medical condition and no previous treatment for the advanced disease. Prior adjuvant chemotherapy and/or radiotherapy was permitted. The patients were required to sign an informed consent and the Ethics Committee of St Chiara University Hospital approved the study.

\section{Treatment plan}

Granulocyte-colony-stimulating factor (G-CSF) $10 \mu \mathrm{g} \mathrm{kg}^{-1} \mathrm{day}^{-1}$ subcutaneously (s.c.) was administered for 5 days to mobilise circulating haemopoietic progenitor cells. When the peripheral blood absolute CD34 + cell count was $\geqslant 50 \mu \mathrm{l}^{-1}$, the aphaeresis procedure was performed using a Fenwall CS 3000 cell separator (Baxter, Chicago, IL, USA). Whole blood $(8-101)$ was processed per procedure using continuous flow blood at a flow rate of $50 \mathrm{ml} \mathrm{min}{ }^{-1}$. A minimum of $12 \times 10^{6} \mathrm{CD} 34+$ cell kg$^{-1}$ were collected from each patient.

Gemcitabine was administered at an FDR of $10 \mathrm{mg} \mathrm{m}^{-2} \mathrm{~min}^{-1}$ at the starting dose of $3000 \mathrm{mg} \mathrm{m}^{-2}$ (starting time infusion $300 \mathrm{~min}$ ). If no dose-limiting toxicity occurred in the first two courses, the dose of gemcitabine was escalated by $500 \mathrm{mg} \mathrm{m}^{-2}$ in cohorts of three patients until maximum tolerable dose. In the absence of toxicity or progression, the courses were repeated every 14 days for a maximum of 12 courses. Peripheral blood progenitors were reinfused $24 \mathrm{~h}$ after each course of chemotherapy. At the time of reinfusion, frozen PBPC were thawed rapidly in a $37^{\circ} \mathrm{C}$ warm bath and reinfused through a central venous catheter: at least $0.5 \times 10^{6}$ $\mathrm{CD} 34+$ cell kg $^{-1}$ were reinfused per course. Following PBPC infusion, G-CSF $5 \mu \mathrm{g} \mathrm{kg}^{-1}$ day ${ }^{-} 1$ s.c. was administered starting day +5 to day +7 .

\section{Safety and activity assessment}

A complete restaging of disease was performed after four, eight and 12 courses of treatment. Definition of response and toxicity were based on WHO criteria. Dose-limiting toxicity of gemcitabine was defined by one of the following criteria: G3 stomatitis lasting more than 5 days, G4 stomatitis and impossibility to recycle on day 14 in more than $40 \%$ of the courses. The MTD of gemcitabine was considered the dose level immediately below that producing one DLT out of three patients.

\section{Pharmacokinetic analysis}

Blood samples (4 ml each) were drawn at the first cycle of gemcitabine administration from an i.v. cannula placed in an antecubital vein before drug administration, after $30 \mathrm{~min}$ and every
$3 \mathrm{~h}$ during infusion and 5, 15, 30, $45 \mathrm{~min}$ and 1, 3, 9, 15 and $24 \mathrm{~h}$ after the end of treatment and collected in heparinised test tubes containing $10 \mu \mathrm{m}$ tetrahydrouridine (Calbiochem, San Diego, CA, USA) to inhibit gemcitabine metabolism by CdA. Plasma was obtained by centrifugation at $5000 \mathrm{~g}$ for $10 \mathrm{~min}$, split in aliquots and stored at $-80^{\circ} \mathrm{C}$.

Plasma levels of gemcitabine and its metabolite $2^{\prime}, 2^{\prime}$-difluorodeoxyuridine (dFdU) were determined by a previously described reverse-phase high-performance liquid chromatography with ultraviolet detection (HPLC-UV) method optimised for the present study (Wang et al, 2003). Drug extraction was performed by adding $80 \mu \mathrm{l}$ of buffer $\left(0.1 \mathrm{moll}^{-1}\right.$ Tris- $\mathrm{HCl}, 50 \mu \mathrm{moll}^{-1} \beta$ mercaptoethanol, $\mathrm{pH} 8.0)$ and $50 \mu \mathrm{l}$ of $40 \%\left(\mathrm{w} \mathrm{v}^{-1}\right)$ trichloroacetic acid (TCA) to $120 \mu \mathrm{l}$ of plasma. Samples were kept on ice for $20 \mathrm{~min}$ and proteins were precipitated by centrifugation for $10 \mathrm{~min}$ at $10000 \mathrm{~g}$. Supernatants were neutralised with $500 \mu \mathrm{l}$ trioctylamine:1,1,2-trichloro-trifluoroethane $(1: 4)$, centrifuged for $1 \mathrm{~min}$ at $10000 \mathrm{~g}$ and $50 \mu \mathrm{l}$ were injected onto a Simmetry Shield $\mathrm{C}_{18}$ $5 \mu \mathrm{m}, 300 \times 4.6 \mathrm{~mm}$ column (Waters, Milford, MA, USA) eluted at a flow rate of $1 \mathrm{ml} \mathrm{min}^{-1}$ with $9 \%$ methanol, $6 \%$ acetonitrile and heptane sulphonic acid $5 \mathrm{~mm}, \mathrm{pH}$ 3.1. The chromatographic apparatus was a Waters LC Module I plus equipped with a WISP 416 autosampler and a variable wavelength UV detector (Waters) set at $270 \mathrm{~nm}$ for peak detection. Calculation of gemcitabine and $\mathrm{dFdU}$ concentration in samples was performed against calibration curves in the range of $0.3-300 \mu \mathrm{moll}^{-1}$ in the plasma of healthy donors. Maximum plasma concentration $\left(C_{\max }, \mu \mathrm{moll}^{-1}\right)$ of gemcitabine and $\mathrm{dFdU}$ were determined from visual inspection of the plasma concentration - time curves, while the area under the plasma concentration-time curve (AUC, $\min \times \mu \mathrm{moll}^{-1}$ ) was calculated with the linear trapezoidal rule.

\section{Pharmacogenomic analysis}

Analysis of CdA enzyme activity Mononuclear cells were obtained by density-gradient centrifugation of patients' blood samples $(14 \mathrm{ml})$, obtained before drug administration, on FicollHypaque (density $1.077 \mathrm{gl}^{-1}$, Pharmacia, Uppsala, Sweden). Cells were resuspended at $3 \times 10^{6}$ cells $100 \mu \mathrm{l}^{-1}$ of buffer $\left(0.1 \mathrm{moll}^{-1}\right.$ Tris- $\mathrm{HCl}, 50 \mu \mathrm{moll}^{-1} \beta$-mercaptoethanol, pH 8.0 (van Haperen et al, 1996). The suspension was sonicated and centrifuged for $20 \mathrm{~min}$ at $10000 \mathrm{~g}$ to obtain crude cytoplasmatic extracts and $10 \mu \mathrm{l}$ of $0.5 \mathrm{mmoll}^{-1}$ gemcitabine was added to $50 \mu \mathrm{l}$ of supernatant and $40 \mu \mathrm{l}$ of buffer. Reaction mixture was incubated for $30 \mathrm{~min}$ at $37^{\circ} \mathrm{C}$ and extraction of analytes was obtained with $25 \mu \mathrm{l} 40 \%$ TCA. Samples were kept on ice for $20 \mathrm{~min}$, neutralised with $250 \mu \mathrm{l}$ tryoctylamine: 1,1,2-trichloro-trifluoroethane $(1: 4)$ and centrifuged for $5 \mathrm{~min}$ at $10000 \mathrm{~g}$. The upper layer was removed and analytes were separated by HPLC, as described above in 'Pharamacokinetic analysis'. Human mononuclear cells from blood donors were the source of cytoplasmatic extracts to be used as a calibrate matrix and spiked with dFdU to generate calibration curves, in the range of $33-1000 \mu \mathrm{moll}^{-1}$. The HPLC method was linear $\left(R^{2}>0.995\right)$ for plasma and cytoplasmatic extracts over the analytical range and the limit of quantitation corresponded to the lower limit of the calibration curves. Intraday variability was $>-2.5$ and $<12 \%$ over the full analytical range of calibration standards, while interday variability was $>-1.5$ and $<15 \%$. Concentrations of dFdU were normalised for cytoplasm protein concentration, which was measured with the Lowry reagent (Sigma, St Louis, MO, USA).

PCR analysis of CdA gene expression Total RNA was extracted using the TRI REAGENT LS (Sigma, St Louis, MO, USA) and dissolved in RNAse-free water containing $10 \mathrm{mmoll}^{-1}$ dithiothreitol and $200 \mathrm{U} \mathrm{ml}^{-1}$ RNase inhibitor (Gibco, Gaithersburg, MD, USA). RNA $(1 \mu \mathrm{g})$ was reverse transcribed at $37^{\circ} \mathrm{C}$ for $1 \mathrm{~h}$ in $100-\mu \mathrm{l}$ reaction volume containing $0.8 \mathrm{~mm}$ dNTPs (Sigma, St Louis, MO, 
USA), $200 \mathrm{U}$ of MMLV-RT (Gibco, Gaithersburg, MD, USA), $40 \mathrm{U}$ of RNase inhibitor and $0.05 \mu \mathrm{g} \mathrm{ml}^{-1}$ of random primers. The cDNA was amplified by quantitative, real-time PCR with the Applied Biosystems $7900 \mathrm{HT}$ sequence detection system (Applied Biosystems, Foster City, CA, USA). PCR reactions were performed in triplicate using $5 \mu \mathrm{l}$ of cDNA, $12.5 \mu \mathrm{l}$ of TaqMan Universal PCR Master Mix (Applied Biosystems), $2.5 \mu \mathrm{l}$ of probe and $2.5 \mu \mathrm{l}$ of forward and reverse primers in a final volume of $25 \mu$ l. Forward (F) and reverse $(\mathrm{R})$ primers and probe $(\mathrm{P})$ were designed with Primer Express 2.0 (Applied Biosystems) on the basis of CdA gene sequence: $5^{\prime}$-TCAAAGGGTGCAACATAGAAAATG-3' (F), 5'-CGG TCCGTTCAGCACAGAT- $3^{\prime}(\mathrm{R})$ and $5^{\prime}$-CTGCTACCCGCTGGG-3' (P) (Demontis et al, 1998). PCR thermal cycling conditions and optimisation of primer concentrations were reported in detail by Giovannetti et al (2004). The amount of target gene, normalised to GAPDH and relative to the calibrator (mononuclear cells from volunteer blood donors), is given as $2^{-\Delta \Delta C_{\mathrm{T}}}$.

\section{Statistics}

Data were expressed as mean values \pm s.d. and the Pearson/ Spearman correlation test and regression analysis were used to demonstrate the relationship between CdA expression, enzyme activity and dFdU AUC. Correlation between response rate and CdA expression and activity level was performed using $\chi^{2}$ test. Overall survival (OS) curves were calculated from the date of diagnosis until the date of death or last follow-up examination according to the Kaplan-Meier method and compared by the logrank test. Variables studied in univariate analysis included CdA expression and activity levels, dFdU AUC, age, sex and drug dose levels. Differences were considered significant if the $P<0.05$.

\section{RESULTS}

\section{Characteristics of the patients}

In all, 25 patients with locally advanced or metastatic pancreatic carcinoma entered into this the study. Two patients were unable to receive the planned treatment due to poor mobilisation of peripheral blood progenitors. A total of 23 patients collected the minimum number of CD34 + cells to support at least one course of treatment. The median age was 56 years (range $42-75$ years) and median performance status (WHO scale) was 0 (range $0-1$ ). Three patients had locally advanced disease, 20 had metastatic disease: two patients had received previous adjuvant chemotherapy with gemcitabine as single agent. Predominant metastatic site was the liver in 14 patients $(60.9 \%)$ (Table 1$)$. The median number of aphaeresis procedure per patients was 3 (range 2-7) and median number of CD34 + cell kg ${ }^{-1}$ collected per aphaeresis was $2.23 \times 10^{6}$ (range $0.15-10.1$ ). Owing to the poor collection after G-CSF only, 15 patients underwent a further mobilisation with gemcitabine $+\mathrm{G}-\mathrm{CSF}$. The average of $\mathrm{CD} 34+$ cell kg $^{-1}$ collected per aphaeresis after G-CSF and after gemcitabine + G-CSF was $2.18 \times 10^{6} \quad$ (s.d. $\left.\pm 1.65 \times 10^{6}\right)$ and $4.12 \times 10^{6} \quad\left(\right.$ s.d. $\left.\pm 2.46 \times 10^{6}\right)$, respectively. The difference was statistically significant $(P=0.0001)$

\section{Toxicity}

Three patients were treated for each dose level from 1st (3000 $\mathrm{mg} \mathrm{m}^{-2}$ in $300 \mathrm{~min}$ ) to 6 th $\left(6000 \mathrm{mg} \mathrm{m}^{-2}\right.$ in $\left.600 \mathrm{~min}\right)$, four patients at 7 th dose level $\left(6500 \mathrm{mg} \mathrm{m}^{-2}\right.$ in $\left.650 \mathrm{~min}\right)$ and one patient at 8 th dose level. A total of 137 courses were administered and were evaluable for toxicity. In all, 15 courses were administered at 1 st level, 19 at 2 nd, 16 at 3 rd, 15 at 4 th, 32 at 5 th, 27 at 6 th, 13 at 7 th and 1 at 8th. G3-4 nonfebrile neutropenia occurred in $2.8 \%$ of courses, G3 anaemia in $6.5 \%$ of courses and G3 thrombocytopenia in $1.5 \%$ of courses. The patient treated at $7000 \mathrm{mg} \mathrm{m}^{-2}$ experienced
Table I Patient characteristics (range)

\begin{tabular}{ll}
\hline No. of patients & 23 \\
M/F & $13 / 10$ \\
Median age (years) & $56(42-75)$ \\
Median ECOG PS & $0(0-1)$ \\
Locally advanced disease (no. of pts.) & 3 \\
Metastatic disease (no. of pts.) & 20 \\
Previous adjuvant CT (no. of pts.) & 2 \\
Median no. of aphaeresis/pt. & $3(2-7)$ \\
Median CD34+ cells kg ${ }^{-1 / a p h a e r e s i s ~}$ & $2.23 \times 10^{6}(0.15-10.1)$ \\
G-CSF & $1.79 \times 10^{6}(0.15-9.12)$ \\
Gemcitabine+G-CSF & $3.61 \times 10^{6}(0.89-10.1)$ \\
No. of total courses & 137
\end{tabular}

ECOG PS = Eastern Cooperative Oncology Group Performance Status; G$\mathrm{CSF}=$ granulocyte-colony-stimulating factor.

Table 2 Toxicities (WHO scale) 137 courses

\begin{tabular}{lcccc}
\hline & GI (\%) & G2 (\%) & G3 (\%) & G4 (\%) \\
\hline Anaemia & $24(17.5)$ & $16(11.6)$ & $9(6.5)$ & - \\
Neutropenia & $2(1.4)$ & $6(4.3)$ & $2(1.4)$ & $2(1.4)$ \\
Thrombocytopenia & $3(4.4)$ & $2(2.9)$ & $1(1.5)$ & - \\
Diarrhoea & - & $2(2.9)$ & - & - \\
Fever & - & $16(11.6)$ & - & - \\
Dermatitis & $5(3.6)$ & - & - & \\
\hline
\end{tabular}

$\mathrm{WHO}=$ World Health Organization

a G4 mucositis and died 25 days after the first course of treatment. Mucositis was considered the dose-limiting toxicity and $6500 \mathrm{mg} \mathrm{m}^{-2}$ was defined as the MTD. Other haematologic and nonhaematologic toxicities were mild or moderate: G2 fever was reported in $11.6 \%$ of courses, G1 dermatitis in $6.4 \%$ and G1 deep venous thrombosis in $2.9 \%$ (Table 2).

\section{Outcome}

In all, 18 patients completed at least four courses of treatment and are evaluable for response. Four patients (22.2\%) achieved an objective response: one patient achieved a complete remission lasting $21+$ months and three patients achieved a partial remission; seven patients $(36.8 \%)$ had a stable disease. Seven patients experienced early progression. Five patients received less than four courses of chemotherapy due to refusal (two patients) and DVT (three patients). According to the intention-to-treat analysis, median time to progression was 4.8 months (95\% CI $1.7-$ 7.9) and median OS was 7.0 months (95\% CI 4.9-9.1); the 1-year survival rate was $21.9 \%$. (Figure 1 ).

Pharmacokinetic analysis The plasma concentration of gemcitabine reached the target concentration of $15 \mu \mathrm{mol} \mathrm{l}^{-1}$ within $30 \mathrm{~min}$ from the start of infusion and remained above this threshold level during the infusion period. The maximum plasma concentration $\left(C_{\max }\right)$ of gemcitabine was achieved at the end of the infusion and ranged from $24.84 \pm 3.93$ to $84.36 \pm 15.97 \mu \mathrm{moll}^{-1}$, suggesting that there was heterogeneity in the plasma kinetics among the patients, whereas the AUC ranged from 5588.72 \pm 1447.85 to $33402.95 \pm 3136.62 \mathrm{~min} \times \mu \mathrm{moll}^{-1}$, showing a dose-dependent increase. Gemcitabine rapidly disappeared from plasma, and $30 \mathrm{~min}$ after the end of drug infusion, only the metabolite dFdU was detectable. $C_{\max }$ of $\mathrm{dFdU}$ ranged from $77.51 \pm 8.70$ to $144.431 \pm 27.79 \mu \mathrm{moll}^{-1}$ and was achieved approximately $15 \mathrm{~min}$ after the end of gemcitabine infusion. The AUC ranged from $36668.76 \pm 3153.76$ to $51314.08 \pm 8958.63 \mathrm{~min} \times \mu \mathrm{moll}^{-1}$, corresponding to the $3000-4500 \mathrm{mg} \mathrm{m}^{-2}$ dose levels; over the 


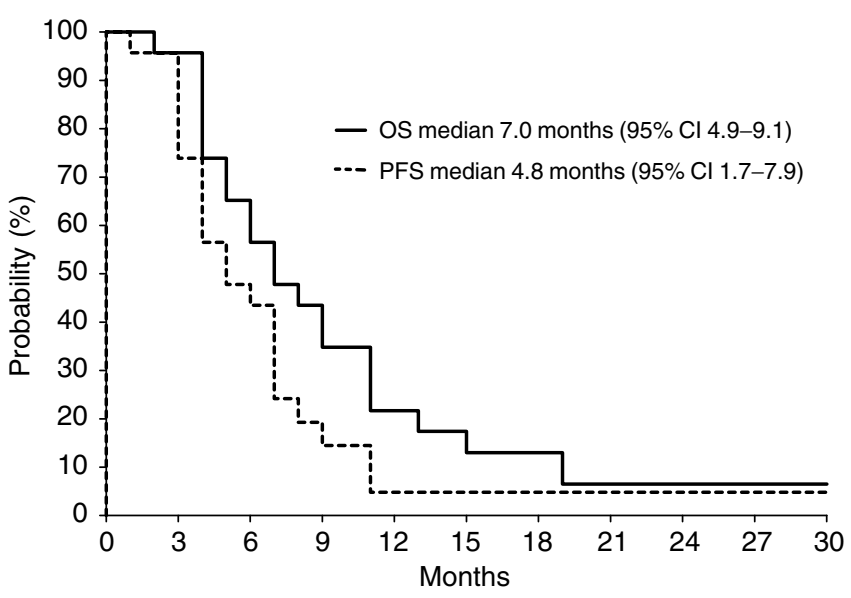

Figure I Progression-free survival (PFS) and overall survival (OS) of 23 patients.

$4500 \mathrm{mg} \mathrm{m}^{-2}$ dose, the AUC of the metabolite did not increase, possibly depending on saturable metabolism (Table 3).

Correlation between CdA gene expression, enzyme activity and $d F d U$ pharmacokinetics CdA gene expression in mononuclear cells from patients showed a 57-fold variation among patients, ranging from 0.56 to 31.67 ; in addition, the enzymatic activity varied from 0.32 to $4.78 \mathrm{nmol} \mathrm{min} \mathrm{mg}^{-1}$ protein. A significant relationship was found between $\mathrm{CdA}$ expression and activity $\left(R^{2}=0.72, P<0.001\right)$, as well as between the plasma AUC of dFdU and CdA expression and its activity $(P<0.05)$ (Figure 2 ).

Relationship between $C d A$ expression, $C d A$ activity and clinical outcome The analysis of CdA expression and activity was performed on 17 patients and 16 of these are evaluable for response. Patients with mononuclear cells' CdA expression level $<10 \mathrm{U}$ and $\mathrm{CdA}$ activity level $<2 \mathrm{nmol} \mathrm{min}^{-1} \mathrm{mg}^{-1}$ protein achieved an objective response (one CR, three PR) or a stable disease (six patients). On the contrary, patients with $\mathrm{CdA}$ expression level $>10 \mathrm{U}$ and $\mathrm{CdA}$ activity level $>2 \mathrm{nmol} \mathrm{min}{ }^{-1} \mathrm{mg}^{-1}$ protein showed an early progression of disease (six patients): the differences are statistically significant with $P<0.05$. In a univariate analysis, patients whose mononuclear cells had CdA expression levels $>10$ (seven patients, median survival time, 3.65 months, $95 \%$ CI $3.31-3.98$ ) had significantly $(P=0.03)$ shorter OS than patients with CdA expression levels $<10$ (10 patients, median survival time, 8.51 months, 95\% CI 6.01-11.00) (Figure 3). Similar results were obtained with CdA activity analysis; patients whose mononuclear cells had CdA activity levels $>2 \mathrm{nmol} \mathrm{min}{ }^{-1} \mathrm{mg}^{-1}$ protein (nine patients, median survival time, 3.98 months, $95 \%$ CI $3.02-4.93$ ) had significantly
$(P=0.006)$ shorter OS than patients with CdA activity levels $<2 \mathrm{nmol} \mathrm{min}{ }^{-1} \mathrm{mg}^{-1}$ protein (eight patients, median survival time, 8.74 months, 95\% CI 3.46-14.02) (Figure 4). In contrast, no significant impact on OS was found both for dFdU AUC $<40.000 \mathrm{~min} \times \mu \mathrm{moll}^{-1}$ and for dose level $>4500 \mathrm{mg} \mathrm{m}^{-2}$. Finally, among the other parameters studied, male sex was associated with shorter survival (median survival time, 5.22 months, 95\% CI 1.758.70 , vs 10.02 months, 95\% CI $3.20-16.84, P=0.04)$, while no significant impact on OS was found for age ( $<56$ years).

\section{DISCUSSION}

The MTD of gemcitabine is strongly associated to the infusion schedule: when administered daily for 5 days over $30 \mathrm{~min}$, the MTD was reached at $9 \mathrm{mg} \mathrm{m}^{-2}$ day $^{-1}$ (O'Rourke et al, 1994); on the other hand, when the drug was administered biweekly, the MTD was observed at $4000 \mathrm{mg} \mathrm{m}^{-2}$ day $^{-1}$ (Brown et al, 1991). In the pivotal trial conducted by Burris et al (1997), gemcitabine produced a response rate of $5.4 \%$, a median survival time of 5.7 months and the clinical benefit response in $23.8 \%$ of the patients. In this trial, gemcitabine was administered on a weekly basis as a 30-min infusion and this schedule has become the standard modality of administration. In a phase I trial, when gemcitabine was administered at FDR to patients with previously treated solid tumours including pancreatic cancer, the MTDs were $1500 \mathrm{mg} \mathrm{m}^{-2}$ over $150 \mathrm{~min}$ (Brand et al, 1997) and $1800 \mathrm{mg} \mathrm{m}^{-2}$ over $180 \mathrm{~min}$ weekly for 3 weeks (Touroutoglou et al, 1998). Preclinical and clinical data suggest that an infusion rate of $10 \mathrm{mg} \mathrm{m}^{-2} \mathrm{~min}^{-1}$ may be more effective even if myelotoxicity can become the doselimiting toxicity (Veerman et al, 1996; Tempero et al, 2003). An FDR of $10 \mathrm{mg} \mathrm{m}^{-2} \mathrm{~min}^{-1}$ can provide plasma concentrations (approximately $20 \mu \mathrm{moll}^{-1}$ ) that are sufficient to maximise the rate of gemcitabine triphosphate accumulation. Two phase I trials have shown that a single course of gemcitabine as FDR infusion of $10 \mathrm{mg} \mathrm{m}^{-2} \mathrm{~min}^{-1}$ for $12 \mathrm{~h}$ can be safely administered alone or in combination with mitoxantrone in patients with relapsed/refractory acute leukaemia (Gandhi et al, 2002; Rizzieri et al, 2002).

The data of our study demonstrate that multiple courses of gemcitabine can be administered at the FDR of $10 \mathrm{mg} \mathrm{m}^{-2} \mathrm{~min}^{-1}$ up to $11 \mathrm{~h}$ every 14 days with peripheral blood stem cell support. Tolerability was excellent with a G4 neutropenia observed in $1.4 \%$ of the courses only, while other haematological and clinical toxicities were $\leqslant$ grade 3 . All the courses were administered at the scheduled 2-week interval. Surprisingly, the first patient treated at the dose level of $7000 \mathrm{mg} \mathrm{m}^{-2}$ developed a severe mucositis and died at day 25 after the first course. It was therefore decided to stop the dose escalation in spite of excellent tolerability experienced by all other patients.

Unfortunately, the activity of this intensive treatment was lower than expected: an objective response was observed in $22.2 \%$ of patients, while a disease control (OR + s.d.) was achieved in $61 \%$ of the patients; median TTP and OS were 4.8 and 7 months,

Table 3 Plasma pharmacokinetics of gemcitabine and dFdU

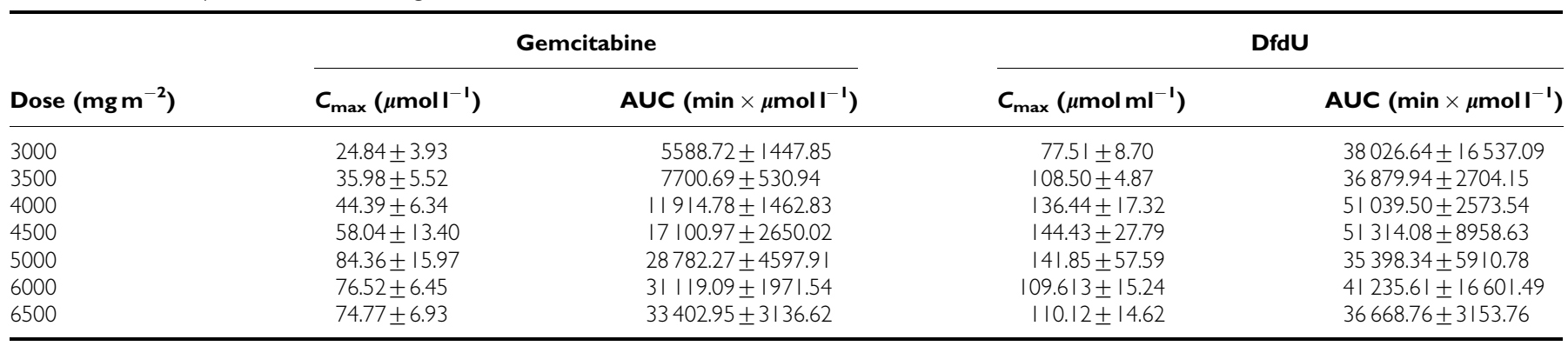



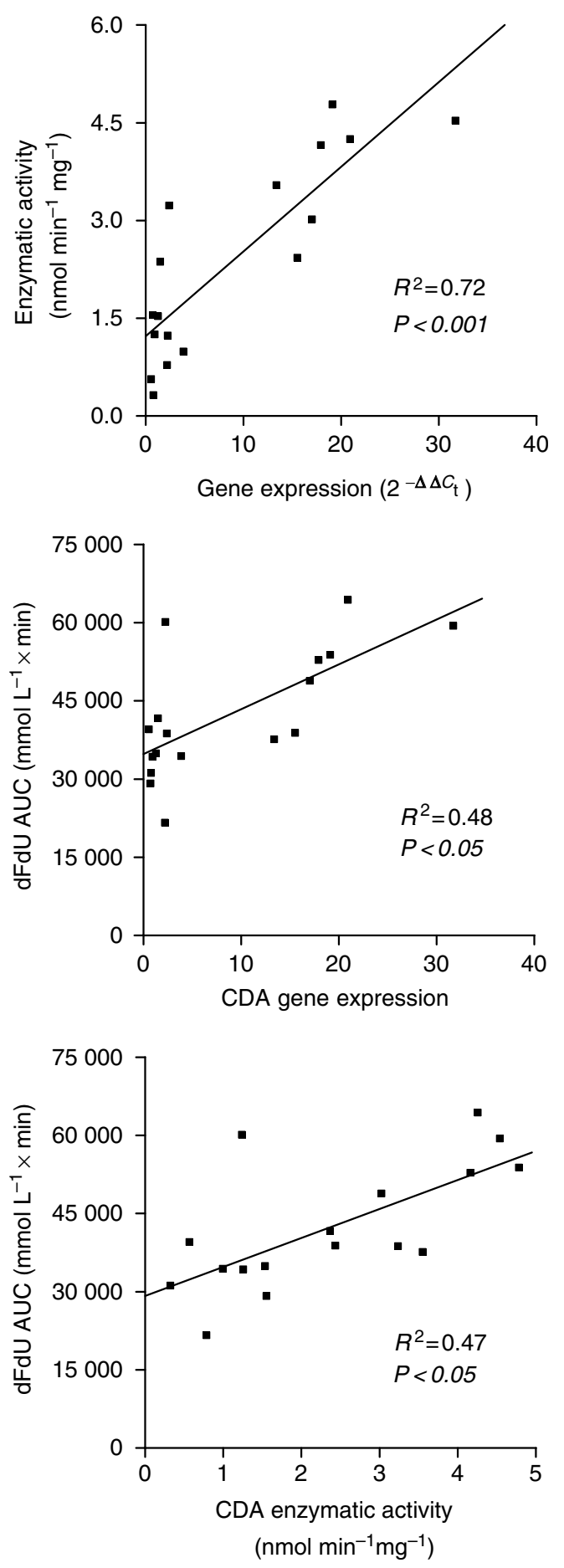

Figure 2 Relation between CDA mRNA expression, enzymatic activity and the AUC of dFdU.

respectively, and 1 year survival rate was $21.9 \%$. These results are inferior to those reported by Tempero et al (2003) with gemcitabine given at FDR of $1500 \mathrm{mg} \mathrm{m}^{-2}$ without peripheral blood stem cell support.

In agreement with Tempero et al, the mean plasma gemcitabine concentration at the end of an FDR infusion of $10 \mathrm{mg} \mathrm{m}^{-2} \mathrm{~min}^{-1}$ was lower than that of the standard 30-min infusion. Conversely, $C_{\max }$ of gemcitabine ranged from $24.84 \pm 3.93$ to $84.36 \pm 15.97 \mu \mathrm{moll}^{-1}$, while in a standard 30 -min infusion with

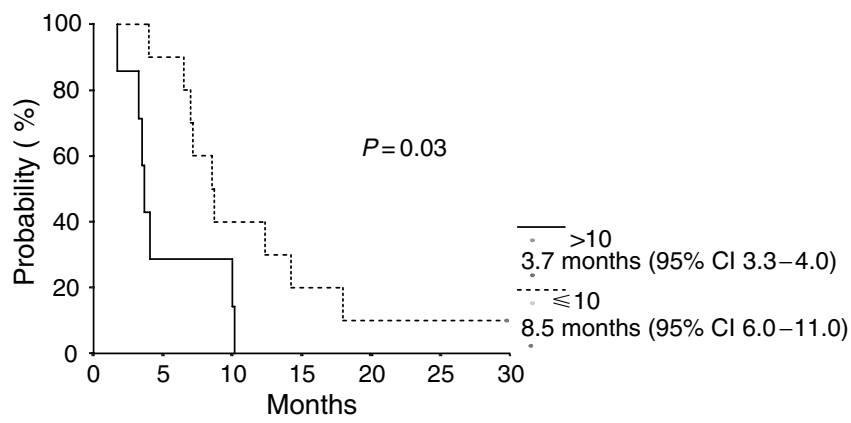

Figure 3 Overall survival analysis according to CdA expression levels: $\leqslant 10$ ( 10 patients) and > 10 (seven patients).

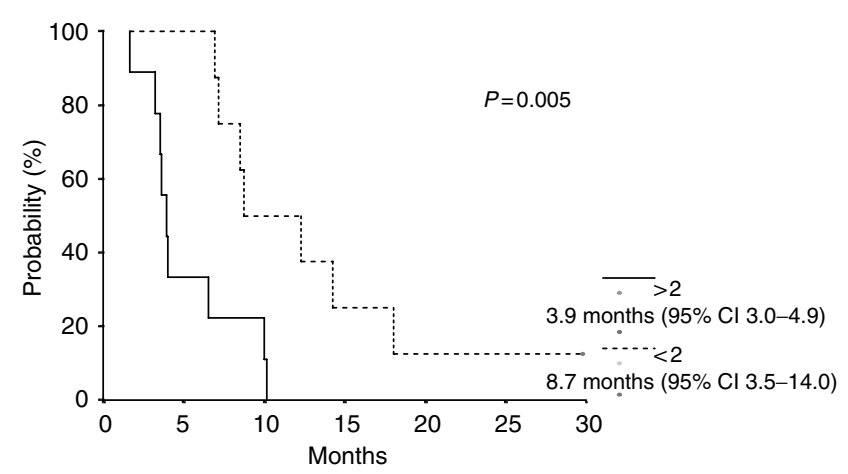

Figure 4 Overall survival analysis according to CdA activity levels:

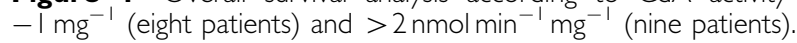

a dose level of $2000 \mathrm{mg} \mathrm{m}^{-2}$, the $C_{\max }$ was $136.17 \pm 49.50 \mu \mathrm{moll}^{-1}$ (De Pas et al, 2000). However, the FDR infusion was able to generate sustained gemcitabine levels in plasma above the threshold of $15 \mu \mathrm{moll}^{-1}$, which is higher than the concentration required to achieve maximal intracellular accumulation of gemcitabine triphosphate; moreover, the gemcitabine AUC showed a dose-dependent increase. In contrast, the AUC of the gemcitabine metabolite showed a dose-dependent increase until the $4500 \mathrm{mg} \mathrm{m}^{-2}$ dose levels; above this dose level, the AUC did not increase, possibly depending on saturable metabolism.

The data of the present study also demonstrate a genotypephenotype correlation between $\mathrm{CdA}$ gene expression, enzyme activity and AUC of the metabolite dFdU produced by gemcitabine deamination by CdA. These findings are in agreement with a previous study by Schroeder et al that demonstrated a significant correlation between the amount of CdA mRNA and enzyme activity in leukaemic blasts, suggesting that variations in CdA activity depends on differences in gene expression. Schroder et al (1998) also showed a correlation of pretherapeutic CdA activity with induction treatment response with the nucleoside analogue cytarabine in patients with acute myeloid leukaemia. Kroep and co-workers have recently shown a clear correlation between dCK levels and gemcitabine sensitivity. In contrast to dCK, CDA activity was not clearly related to gemcitabine sensitivity (Kroep et al, 2002).

In the present study, an univariate analysis demonstrated that patients whose mononuclear cells had higher CdA expression and activity levels had significantly higher rate of early progression and shorter OS than patients with lower CdA expression and activity levels, suggesting that gemcitabine metabolism in mononuclear cells could predict clinical outcome. The small number of patients in our study does not allow a multivariate analysis. 
In conclusion, gemcitabine given as an FDR infusion of $10 \mathrm{mg} \mathrm{m}^{-2} \mathrm{~min}^{-1}$ in pancreatic cancer patients is feasible with peripheral blood cell support up to $650 \mathrm{~min}$ and the dose of $6500 \mathrm{mg} \mathrm{m}^{-2}$ is the MTD. No severe toxicities were observed at this dose; however, the activity does not seem to be better than that reported with other less intensive FDR schedules. Pharmacokinetic data demonstrate a correlation between dose of gemcitabine and its AUC; on the contrary, AUC of dFdU showed a plateau over $4500 \mathrm{mg} \mathrm{m}^{-2}$ of gemcitabine, possibly depending on saturable metabolism. The observed relationship between CdA expression and activity in mononuclear cells and treatment activity if confirmed might be useful to discriminate patients at different prognosis.

\section{ACKNOWLEDGEMENTS}

This work was supported by a grant from Eli-Lilly, Indianapolis, IN, USA.

\section{REFERENCES}

Abbruzzese JL, Grunewald R, Weeks EA, Gravel D, Adams T, Nowak B, Mineishi S, Tarassoff P, Satterlee W, Raber MN (1991) A phase I clinical, plasma and cellular pharmacology study of gemcitabine. J Clin Oncol 9: $491-498$

Brand R, Capadano M, Tempero M (1997) A phase I trial of weekly gemcitabine administered as prolonged infusion in patients with pancreatic cancer and other solid tumors. Invest New Drugs 15: 331 - 341

Brown T, O’Rourke T, Burris H, Kuhn J, Tarasoff P, Cagnola J, Rodriguez G, Von Hoff D (1991) A phase I trial of gemcitabine (LY188011) administered intravenously every two weeks. Proc Am Soc Clin Oncol 10: 115 (abstr. 328)

Burris HA, Moore MJ, Andersen J, Green MR, Rothemberg ML, Modiano MR, Cripps MC, Portenov RK, Storniolo AM, Trassoff P, Nelson R, Dorr FA, Stephens CD, Von Hoff DD (1997) Improvements in survival and clinical benefit with gemcitabine as first-line therapy for patients with advanced pancreas cancer: a randomized trial. J Clin Oncol 15: $2403-2413$

Csoka K, Liliemark J, Larsson R, Nygren P (1995) Evaluation of the cytotoxic activity of gemcitabine in primary cultures of tumor cells from patients with hematologic or solid tumors. Semin Oncol 22(4 Suppl 11): $47-53$

Demontis S, Terao M, Brivio M, Zanotta S, Brischi M, Garattini E (1998) Isolation and characterization of the gene coding for human cytidine deaminase. Biochim Biophys Acta 1443: $323-333$

De Pas T, De Braud F, Danesi R, Sessa C, Catania C, Curigliano G, Fogli S, Del Tacca M, Zampino G, Sbanotto A, Rocca A, Cinieri S, Marrocco E, Milani A, Goldhirsch A (2000) Phase I and pharmacologic study of weekly gemcitabine and paclitaxel in chemonaive patients with advanced non-small cell lung cancer. Ann Oncol 11: 821-827

Evans DB, Abbruzzese JL, Rich TA (1997) Cancer of the pancreas. In Cancer: Principles and Practice of Oncology De Vita Jr VT, Hellman S, Rosenberg SA (eds) pp 1054-1087. Philadelphia, PA: Lippincott-Raven

Gandhi V, Plunkett W, Du M, Ayres M, Estey EM (2002) Prolonged infusion of gemcitabine: clinical and pharmacodynamic studies during a phase I trial in relapsed acute myelogenous leukemia. J Clin Oncol 20: $665-673$

Giovannetti E, Mey V, Danesi R, Mosca I, Del Tacca M (2004) Synergistic cytotoxicity and pharmacogenetics of gemcitabine and pemetrexed combination in pancreatic cancer cell lines. Clin Cancer Res 10: $2936-2943$

Grunewald R, Abbruzzese JL, Tarassoff P, Plunkett W (1991) Saturation of $2^{\prime}, 2^{\prime}$-difluorodeoxycytidine $5^{\prime}$-triphosphate accumulation by mononuclear cells during a phase I trial of gemcitabine. Cancer Chemother Pharmacol 27: 258-262

Grunewald R, Kantarjian H, Du M, Faucher K, Tarassoff P, Plunkett W (1992) Gemcitabine in leukemia: a phase I clinical, plasma, and cellular pharmacology study. J Clin Oncol 10: 406-413

Grunewald R, Kantarjian H, Keating MJ, Abbruzzese J, Tarassoff P, Plunkett W (1990) Pharmacologically directed design of the dose rate and schedule of $2^{\prime}, 2^{\prime}$-difluorodeoxycytidine (gemcitabine) administration in leukemia. Cancer Res 50: 6823-6826

Huang P, Chubb S, Hertel LW, Grindey GB, Plunkett W (1991) Action of 2', $2^{\prime}$-difluorodeoxycitidina on DNA synthesis. Cancer Res 51: 6110-6117
Kroep JR, Loves WJ, van der Witt CL, Alvarez E, Talianidis I, Boven E, Braakhuis BJ, van Groeningen CJ, Pinedo HM, Peters GJ (2002) Pretreatment deoxycytidina kinase levels predict in vivo gemcitabine sensitivity. Mol Cancer Therap 1: 371-376

O'Rourke T, Brown T, Havlin K, Kuhn JG, Craig JB, Burris HA, Satterlee WG, Tarassoff P, Von Hoff DD (1994) Phase I clinical trial of gemcitabine given as an intravenous bolus on 5 consecutive days. Eur J Cancer 30A(3): $417-418$

Palmer KR, Kerr M, Knowles G, Cull A, Carter DC, Leonard RC (1994) Chemotherapy prolongs survival in inoperable pancreatic cancer. $\mathrm{Br} J$ Surg 81: $882-885$

Pollera CF, Ceribelli A, Crecco M, Oliva C (1997) Prolonged infusion gemcitabine: a clinical phase I study at low $\left(300 \mathrm{mg} \mathrm{m}^{-2}\right)$ and high dose $\left(875 \mathrm{mg} \mathrm{m}^{-2}\right)$ levels. Invest New Drugs 15: $115-121$

Poplin EA, Corbertt T, Flaherty L, Tarassoff P, Redman BG, Valdivieso M, Baker L (1992) Difluorodeoxycytidine (dFdC, gemcitabine): a phase I study. Invest New Drugs 10: 165-170

Rizzieri DA, Bass AJ, Rosner GL, Gockerman JP, DeCastro CM, Petros WP, Adams DJ, Laughlin MS, Davis P, Foster T, Jacobson R, Hurwitz H, Moore JO (2002) Phase I evaluation of prolonged-infusion gemcitabine with mitoxantrone for relapsed or refractory acute leukemia. J Clin Oncol 20: $674-679$

Rothenberg ML, Moore MJ, Cripps MC, Andersen JS, Portenoy RK, Burris HA, Green MR, Tarassoff PG, Brown TD, Casper ES, Storniolo AM, Von Hoff DD (1996) A phase II trial of gemcitabine in patients with 5-FU-refractory pancreas cancer. Ann Oncol 7: 347-353

Schroder JK, Kirch C, Seeber S, Schutte J (1998) Structural and functional analysis of the cytidine deaminase gene in patients with acute myeloid leukaemia. Br J Haematol 103: 1096-1103

Tempero M, Plunkett W, Ruiz van Haperen V, Hainsworth J, Hochester H, Lenzi R, Abbruzzese J (2003) Randomized phase II comparison of dose intense Gemcitabine: thirty-minute infusion and fixed dose rate infusion in patients with pancreatic adenocarcinoma. J Clin Oncol 21: $3402-3408$

Touroutoglou N, Gravel D, Raber MN, Plunkett W, Abbruzzese JL (1998) Clinical results of pharmacodynamically-based strategy for higher dosing of gemcitabine in patients with solid tumors. Ann Oncol 9: 1003-1008

van Haperen VW, Veerman G, Vermorken JB, Pinedo HM, Peters G (1996) Regulation of phosphorylation of deoxycytidine and $2^{\prime}, 2^{\prime}$-difluorodeoxycytidine (gemcitabine); effects of cytidine $5^{\prime}$-triphosphate and uridine $5^{\prime}$-triphosphate in relation to chemosensitivity for $2^{\prime}, 2^{\prime}$-difluorodeoxycytidine. Biochem Pharmacol 51: $911-918$

Veerman G, Ruiz van Haperen VW, Vermorken JB, Noordhuis P, Braakhuis BJ, Pinedo HM, Peters GJ (1996) Antitumor activity of prolonged as compared with bolus administration of $2^{\prime}, 2^{\prime}$-difluorodeoxycytidine in vivo against murine colon tumors. Cancer Chemother Pharmacol 38: $335-342$

Von Hoff DD (1996) Activity of gemcitabine in a human tumor cloning assay as a basis for clinical trials with gemcitabine: San Antonio Drug Development Team. Invest New Drugs 14: 265-270

Wang LZ, Goh BC, Lee HS, Noordhuis P, Peters GJ (2003) An expedient assay for determination of gemcitabine and its metabolite in human plasma using isocratic ion-pair reversed-phase high-performance liquid chromatography. Therapeut Drug Monit 25: $552-557$ 